\title{
$X X$. Hydraulic investigations, subservient to an intended Croonian Lecture on the motion of the blood
}

Thos Young M.D. For. Sec. R.S.

To cite this article: Thos Young M.D. For. Sec. R.S. (1809) XX. Hydraulic investigations, subservient to an intended Croonian Lecture on the motion of the blood, Philosophical Magazine Series 1, 33:130, 123-133, DOI: 10.1080/14786440908562834

To link to this article: http://dx.doi.org/10.1080/14786440908562834

Published online: 18 May 2009.

Submit your article to this journal $₫$

Џll Article views: 4

Q View related articles $\longleftarrow$ 
stance carefully converted into charcoal, and aftcrwards applied to the same purpose. The substances being so varied and numerous that contain the oxice of carbon, it could not possibly follow that the extent of their carbonaceous effects would be in the proportion of their masses under similar circumstances, nor that the charcoal or oxide that each of them afforded by distillation would bear the same relation to each other in point of purity, even where the acknowledged quantity of alloy in the state of earths, salts, \&c., were the same. We therefore find, that even in the state of the raw substance equal weights or quantities of matter, calculating always upon the residuum alloys of different substances, produce results materially different, which can only be attributable to the different existing state of the oxide, or to the decomposition of the hydro-carbonate which most of them contain. The difference of the results becomes much greater when the oxide of carbon is used in the state of charcoal or coke, and the variety of the results here also obtained, where no hydro-carbonate comes into action, can only be placed to the state of oxidation of the carbon.

In a future communication I shall illustrate, by some experiments, what I have just stated.

XX. Hydraulic Investigations, subservient to an intended Croonian Lecture on the Motion of the Blood. By Thos. Young, M.D. For. Sec. R.S.*

I. Of the Friction and Discharge of Fluids running in Pipes, and of the Velocity of Rivers.

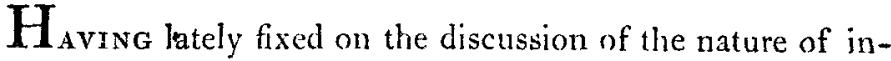
flammation, for the subject of an academical exercise, I found it necessary to examine attentively the mechanical principles of the circulation of the blood, and to investigate minutely and comprehensively the motion of fluids in pipes, as affected by friction, the resistance occasioned by flexure, the laws of the propagation of an impulse through the fluid

* From Philosophical Transactions for 1808 . 
contained in an elastic tube, the magnitude of a pulsation in different parts of a conical vessel, and the effect of a contraction advancing progressively through the length of a given canal. The phy siological application of the results of these inquiries I shall bave the honour of laying before the Royal Society at a future time; but I have thought it advisable to communicate, in a separate paper, such conclusions, as may be interesting to some persons, who do not concern themselves with disquisitions of a physiological nature; and I imagine it may be as agreeable to the Society that they should he submitted at present to their consideration, as that they should be withheld until the time appointed for the delivery of the Croonian Lecture.

It has been observed by the late Professor Robison, that the comparison of the Chevalier Dubuat's calculations with his experiments is in all respects extremely satisfactory; that it exhibits a beautiful specimen of the means of expressing the general result of an extensive series of observations in an analytical formula, and that it does honour to the penetration, skill, and address of Mr. Dubuat, and of Mr. de St. Honoré, who assisted him in the construction of his expressions. I am by no means disposed to dissent from this encomium; and I agree with Professor Robison, and with all otber late authors on hydraulics, in applauding the unusually accurate coincidence between these theorems and the experiments from which they were deduced. But I have already taken the liberty of remarking, in my lecture on the history of hydraulics, that the form of these expressions is by no means so convenient for practice as it might have been rendered; and they are also liable to still greater objections in particular cases, since, when the pipe is either extremely narrow, or extremely long, they become completely erroneous : for notwithstanding Mr. Dubuat seems to be of opinion, that a canal may bave a finite inclination, and yet the water contained in it may remain perfectly at $r e s t$, and that no force can be sufficient to make water flow in any finite quantity through a tube less than one twentyfifth of an inch in diameter; it can scarcely require an argument to show, that he is mistaken in both these respects. 
It was therefore necessary for my purpose to substitute, for the formulæ of Mr. Dubuat, others of a totally different nature; and I could follow Dubuat in nothing but in his general mode of considering a part of the pressure, or of the height of a given reservoir, as employed in overcoming the friction of the pipe through which the water flows out of it; a principle, which, if not of his original invention, was certainly first reduced by him into a practical form. By comparing the experiments, which he has collected, with some of Gerstner's, and sonse of my own, I bave ultimately discovered a formula, which appears to agree fully as well as Dubuat's with the experiments from which his rules were deduced, which accords better with Gerstner's experiments, which extends to all the extreme cases with equal accuracy, which seems to represent more simply the actual operation of the forces concerned, and which is direct in its application to practice, without the necessity of any successive ap. proximations.

I began by examining the velocities of the water discharged through pipes of a given diameter with different degrees of pressure; and I found, that the friction could not be represented by any single power of the velocity, although it frequently approached to the proportion of that power of which the exponent is 1.8 ; but that it appeared to consist of two parts, the one varying simply as the velocity, the other as its square. The proportion of these parts to each other must however be considered as different in pipes of different diameters, the first part being less perceptible in very large pipes, or in rivers, but becoming greater than the second in very minute tubes; while the second also becomes greater for each given portion of the interual surface of the pipe, as the diameter is diminished.

If we express, in the first place, all the measures in French inches, calling the height employed in overcoming the friction $f$, the velocity in a secund $v$, the diameter of the pipe $d$, and its length $l$, we may make $f=a \frac{l}{d} v^{2}+2 c_{d}^{l} v$; for it is obvious, that the friction must be directly as the length of the pipe; and since the pressure is proportional 
to the area of the section, and the surface producing the friction to its circumference or diameter, the relative magnitude of the friction must also be inversely as the diameter, or nearly so, as Dubuat has justly observed. We shall then find that $a$ must be $0000001\left(430+\frac{75}{d}-\frac{1440}{d+12}-\frac{180}{d+\frac{1}{3}}\right)$, and $c=0000001\left(\frac{900 d d}{d d+1000}+\frac{1}{\sqrt{ } d}\left(1050+\frac{12}{d}+\frac{9}{d d}\right)\right)$. Hence it is easy to calculate the velocity for any given pipe or river, and with any given head of water. For the height required for producing the velocity, independently of friction, is, according to Dubuat, $\frac{v^{2}}{478}$, or rather, as it appears from almost all the experiments which 1 bave compared, $\frac{v^{2}}{550}$ : and the whole height $h$ is therefore equal to $f+\frac{v^{2}}{550}$, or $h=\left(\frac{a l}{d}+\frac{1}{550}\right) v^{2}+\frac{2 c l}{d} v$; and making $b=\frac{1}{a l: d+00182}$, and $e=\frac{b c l}{d}, v^{2}+2 e v=b h$, whence $v=\sqrt{ }\left(b h+e^{2}\right)-e$. In order to adapt this formula to the case of rivers, we. must make $l$ infinite; then $b$ becomes $\frac{d}{a l}$ and $b h=\frac{d}{a} \cdot \frac{h}{l}$ $=\frac{d s}{a}$, s being the sine of the inclination, and $d$ four times the hydraulic mean depth; and since $e$ is here $=\frac{c}{a}, v=$ $\frac{v(a d s+c c)-c}{a}$, and in most rivers, $v$ becomes nearly $\checkmark(20000 d s)$.

In order to show the agreement of these formulæ with the result of observation, I have extracted, as indiscriminately and impartially as possible, forty of the experiments made and collected by Dubuat; I have added to these some of Gerstner's, with a few of my own; and I have compared the results of these experiments with Dubuat's calculations, and with my own formulæ, in separate columns. There are six of Dubuat's experiments, which he bas rejected as irregular, apparently without any very sufficient reason, since he has accidentally mentioned, that some of them were made with great care: I have therefore calculated the velocities for these experiments in both ways, and compared the results in a separate table.

Tabular 
Talular Comparison of Hydraulic Experiments.

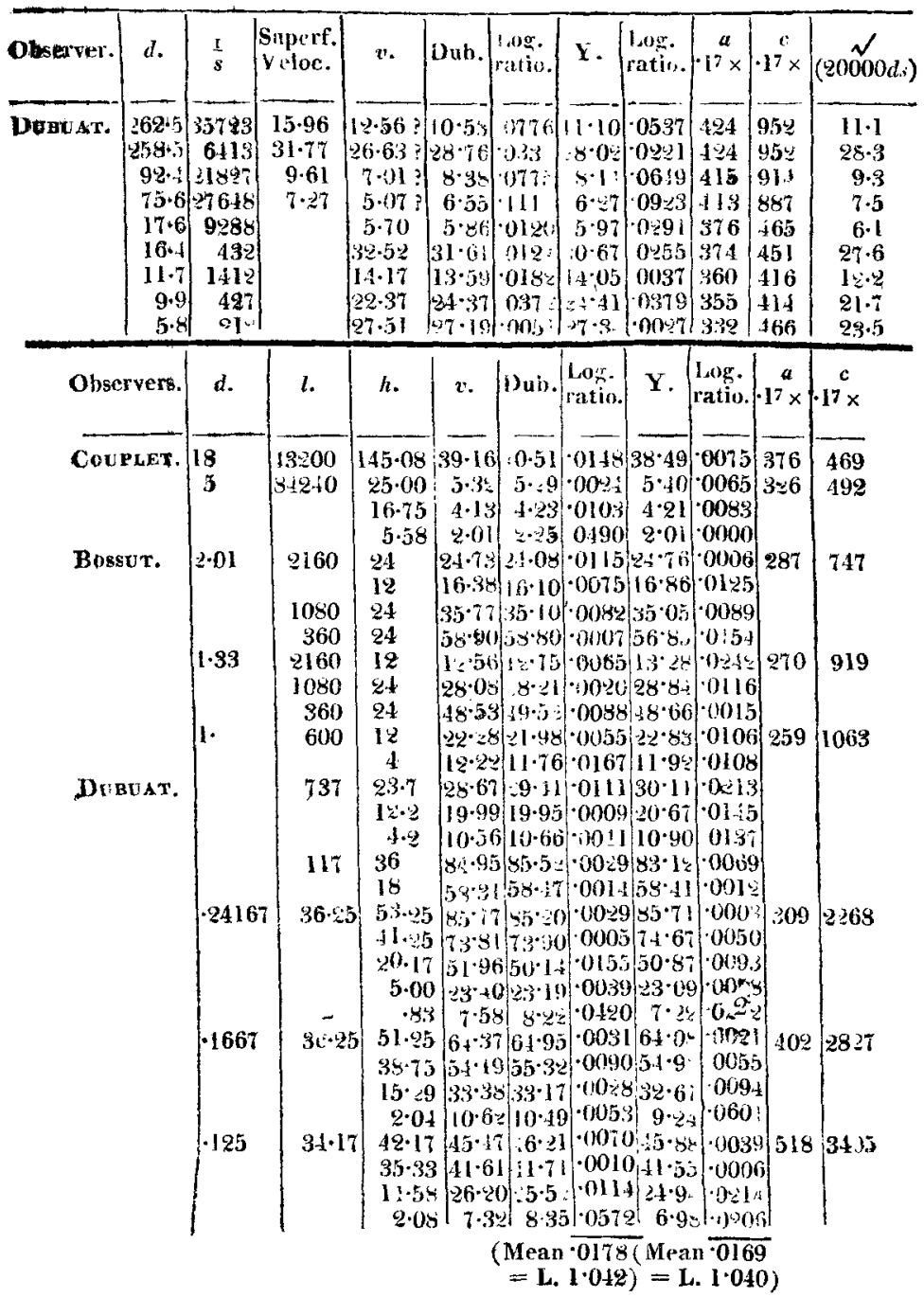




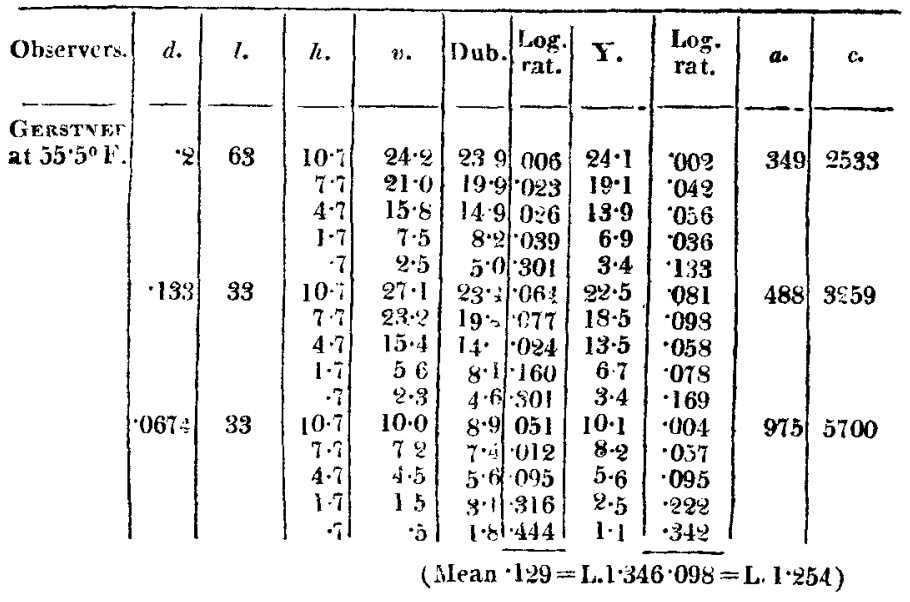

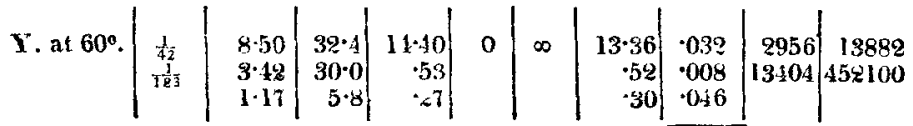

$$
\begin{aligned}
& \text { (Mean } 0 \% 9=\text { L. } 1.068
\end{aligned}
$$

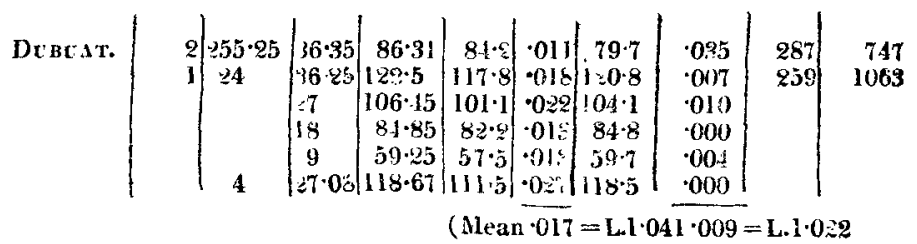

It appears $t o m$ this comparison, that in the forty experiments extracted from the collection, which served as a basis for Dubuat's calculations, the mean error of his formula is $\frac{1}{x^{4}}$ of the whole velocity, and that of mine $\frac{1}{\frac{1}{3}}$ only; but if we omit the four experiments, in which the superficial velocity only of a river was observed, and in which I have calculated the mean velocity by Dubuat's rules, the mean error of the remaining 36 is $\frac{1}{33}$, according to ny mode of calculation, and $\frac{1}{37}$ according to Mr. Dubuat's ; so that, on the whole, the accuracy of the two formula may be considered as precisely equal with respect to these experiments. In the six experiments which Dubuat has wholly rejected,

the 
the mean error of his formula is about $\frac{1}{4}$, and that of mine $\frac{1}{45}$. In fifteen of Gerstner's experiments, the mcan error of Dubuat's rule is one third, that of mine one fourh ; and in the three experiments which I made with very fine tubes, the error of my own rules is one fifteenth of the whole, while in such cases Dubuat's formulx completely fail. I have determined the mean error by adding together the logarithmic ratios of all the results, and dividing the sum by the number of experiments. It would be useless to seek for a much greater degree of accuracy, unless it were probable, that the errors of the experiments themselves were less than those of the calculations; but if a sufficient number of extrcmely accurate and frequently repeated experiments conld be obtained, it would be very possible to adapt my formula still more correctly to their results.

In order to facilitate the computation, I have made a table of the coefficients $a$ and $c$ for the different values of $d$, all the measures being still expressed in French inches.

Table of Coefficients for French Inches.

\begin{tabular}{|c|c|c|c|c|c|c|c|c|}
\hline$d$ & $\cdot^{a}{ }^{7} \times$ & $\cdot 1^{c} \times$ & $d$ & $\begin{array}{c}a \\
\cdot 1^{7} \times\end{array}$ & $\int^{c} 1^{7} \times$ & $d$ & $\int^{a} 1^{7} \times$ & $\mid \begin{array}{c}c \\
\cdot 1^{7} \times\end{array}$ \\
\hline$\infty$ & 430 & 900 & 15 & 370 & 427 & $\cdot 7$ & 249 & 1278 \\
\hline 500 & 427 & 943 & 10 & 354 & 414 & $\cdot 6$ & 248 & 1384 \\
\hline 400 & 426 & 946 & 9 & 350 & 421 & $\cdot 5$ & 249 & 1524 \\
\hline 300 & 423 & 950 & 8 & 345 & 433 & $\cdot 4$ & 257 & 1717 \\
\hline 200 & 421 & 951 & 7 & 340 & 440 & $\frac{1}{3}$ & 268 & 1895 \\
\hline 100 & 416 & 923 & 6 & 335 & 469 & $\cdot 3$ & 979 & 2008 \\
\hline 90 & 415 & 911 & 5 & 325 & 512 & 1 & 303 & 2225 \\
\hline 80 & 413 & 896 & 4 & 319 & 540 & 2 & 349 & 2532 \\
\hline 70 & 410 & 872 & 3 & 305 & 617 & & 402 & 2827 \\
\hline 60 & 408 & 840 & $2 \cdot 5$ & 296 & 687 & $\cdot 15$ & 440 & 3026 \\
\hline 50 & 406 & 792 & 2 & 288 & 751 & $1 \frac{1}{7}$ & 458 & 3116 \\
\hline 40 & 400 & 719 & 1.5 & 275 & 866 & $\frac{i}{8}$ & 518 & 3405 \\
\hline 30 & 393 & 618 & 1 & 259 & 1063 & $\frac{1}{9}$ & 589 & 3693 \\
\hline 25 & 387 & 560 & $\cdot 9$ & 955 & 1123 & $\cdot 1$ & 646 & 3985 \\
\hline 20 & 380 & 492 & $\cdot 8$ & 252 & 1103 & & & \\
\hline
\end{tabular}

For example, in the Jast experiment, where $d$ is $1, l 4$, and $h 27 \cdot 1$, we have $a \leqslant \cdot 0000259, b=\frac{1}{a l: d+\cdot 00182}=$ Vol. 33. No. 130. Fl. 1809 . 
516, $c=\cdot 0001063, e=b c l: d=\cdot 22$, and $v=\sqrt{ }\left(b h+e^{2}\right)$ $-e=118 \cdot 46$, which agrees with the experiment within $\frac{1}{500}$ of the whole. I had at first employed for $a$ the formula $\frac{430}{1+1}:+\frac{57}{d}+\frac{1}{6 d d}$, but I found that the value, thus determined, became too great when $d$ was about 20 , and too small in some other cases. Coulomb's experiments on the friction of fluids, made by means of the torsion of wires, give about $\cdot 00014$ for the value of $c$, which agrees as nearly with this table, as any constant number could be expected to do. I have however reason to think, from some experiments communicated to me by Mr. Rubertson Buchanan, that the value of $a$, for pipes about balf an inch in diameter, is somewhat too small; my mode of calculation, as well as Dubuat's, giving too great a velocity in such cases.

If any person should be desirous of making use of $\mathrm{Du}$ buat's formula, it would still be a great convenience to begin by determining $v$ according to this method; then, taking $b=\frac{l}{h-v^{2}: 478}$, or rather, as Langsdorf makes it, $b=$ $\frac{l}{h-v^{4}: 482}$, to proceed in calculating $v$ by the formula $v$ $=148.5(\sqrt{ } d-2) \cdot\left(\frac{1}{\sqrt{b-\text { H. L. } \sqrt{ }(b+1 \cdot 6)}}-\cdot 001\right)$, since this determination of $b$ will, in general, be far more accurate than the simple expression $b=\frac{l+45 d}{h}$, and the continued repetition of the calculation, with approximate values of $v$, may thus be avoided. Sometimes, indeed, the values of $v$ found by this repetition will constitute a diverging instead of a converging series, and in such cases we can only employ a conjectural value of $v$, intermediate between the two preceding ones.

Having sufficiently examined the accuracy of my formula, I shall now reduce it into English inches, and shall add a second table of the coefficients, for assisting the calculation. In this case, $a$ becomes $0000001\left(413+\frac{75}{d}-\right.$ $\left.\frac{1440}{d+12 \cdot 8}-\frac{180}{d+355}\right), c=\cdot 0000001\left(\frac{900 d d}{d d+1136}+\frac{1}{\sqrt{d}}\right.$ 
$\left(1085+-\frac{13 \cdot 21}{d}+\frac{1 \cdot 0563}{d d}\right)$, and $b=\frac{1}{a l: d+\cdot 00171}, \epsilon$ being $\frac{d c l}{d}$, and $v=\sqrt{ }\left(b h+e^{3}\right)-e$, or $=\sqrt{ }\left(\frac{d s}{a}+\frac{c c}{a a}\right)-\frac{c}{a}$, as before; and in either case the superficial velocity of a riwer may be found, very nearly, by adding to the mean velocity $v$ its square root, and the velocity at the bottom by subtracting it.

Talle of Coefficients, for Engiish Inches.

\begin{tabular}{|c|c|c|c|c|c|c|c|c|}
\hline$d$ & $1^{a} \times$ & $\mid \begin{array}{c}c \\
1^{7} \times\end{array}$ & $d$ & $\operatorname{c}^{a}{ }^{7} \times$ & $1^{c} \times$ & $d$ & $1^{a}$ & $c^{c}$ \\
\hline$\infty$ & 413 & 900 & 15 & 354 & 430 & $\cdot 7$ & 243 & 1322 \\
\hline 500 & 410 & 944 & 10 & 339 & 413 & $\cdot 6$ & $\$ 43$ & 1433 \\
\hline 400 & 409 & 948 & 9 & 336 & 421 & $\cdot 5$ & 245 & 1578 \\
\hline 300 & 406 & 951 & 8 & 331 & 433 & $\cdot 4$ & 254 & 1779 \\
\hline 200 & 404 & 951 & 7 & $32 \pi$ & 449 & $\frac{1}{3}$ & 268 & 1963 \\
\hline 100 & 399 & 918 & 6 & 322 & 471 & $\cdot 3$ & 280 & 2082 \\
\hline 90 & 398 & 903 & 5 & 312 & 507 & $\frac{1}{4}$ & 305 & 2307 \\
\hline 80 & 396 & 885 & 4 & 306 & .556 & $\cdot 2$ & 354 & 2631 \\
\hline 70 & 393 & 860 & 3 & 292 & 635 & $\bar{\sigma}$ & 409 & 2943 \\
\hline 60 & 391 & 825 & $2 \cdot 5$ & 284 & 694 & $\cdot 15$ & 447 & 3150 \\
\hline 50 & 389 & 772 & 2 & 277 & 774 & $\frac{1}{7}$ & 466 & 3251 \\
\hline 40 & 383 & 698 & $1 \cdot 5$ & 966 & 894 & $\frac{7}{8}$ & 528 & 3558 \\
\hline 30 & 377 & 597 & 1 & 251 & 1099 & $\frac{1}{9}$ & 599 & 3866 \\
\hline 25 & 371 & 526 & $\cdot 9$ & 248 & 1161 & $\cdot 1$ & 657 & 4183 \\
\hline 20 & 364 & 482 & $\cdot 8$ & 245 & 1234 & & & \\
\hline
\end{tabular}

II. Of the Resistance occasioned by Flexure in Pipes or Rivers.

Mr. Dubuat has made some experiments on the effect of the flexure of a pipe in retarding the motion of the water flowing through it; but they do not appear to be by any means sufficient to anthorise the conclusions which he has drawn from them. He directs the squares of the sines of the angles of Hexure to be collected into one sum, which, being multiplied by a certain constant coefficient, and by the square of the velocity, is to show the height required for overcoming the resistance. It is, however, easy to see, that such a rule must be fundamentally erroneous, and its coin- 
cidence with some experiments merely accidental, since the results afforded by it must vary according to the method of stating the problem, which is entirely arbitrary. Thus it depended only on Mr. Dubuat to consider a pipe bent to an angle of $144^{\circ}$ as consisting of a single flexure, as composed of two flexures of $72^{\circ}$ each, or of a much greater number of smaller flexures; although the result of the experiment would only agree with the arbitrary division into two parts, which he has adopted. This difficulty is attached to every mode of computing the effect either from the squares of the sines or from the sines themselves; and the only way of avoiding it is to attend merely to the angle of flexure as expressed in degrees. It is natural to suppose, that the effect of the curvature must increase, as the curvature itself increases, and that the retardation must be inversely proportional to the radius of curvature, or very nearly so; and this supposition is sufficiently confirmed by the experiments which Mr. Dubuat has employed in support of a theory so different. It might be expected, that an equal curvature would create a greater resistance in, a larger pipe than in a smaller, since the inequality in the motions of the different parts of the fluid is greater; but this circumstance does not seem to have influenced the results of the experiments made with pipes of an inch and of two inches diameter: there must also be some deviation from the general law in cases of very small pipes having a great curvature, but this deviation cannot be determined without further experiments. Of the 25 which Dubuat has made, he has rejected ten as irregular, because they do not agree with his theory: indeed four of them, which were made with a much shorter pipe than the rest, differ so manifestly from them, that they cannot be reconciled: but five others agree sufficiently, as well as all the rest, with the theory which I have here proposed, supposing the resistance to be as the angular flexure, and to increase besides almost in the same proportion as the radius of curvature diminishes, but more nearly as that power of the radius of which the index is $\frac{7}{8}$. Thus if $p$ be the number of degrees subtended at the centre of flexure, and $q$ the radius of curvatire of the axis of the pipe in French inches, we 
shall have $r=\frac{p v^{2}}{200000 q}$ nearly, or, more accuratcly, $r=$ $\frac{0000045 p v^{9} q \frac{1}{1}}{q}$. These calculations are compared with the whole of Dubuat's experiments in the following table.

Table of Experiments on the Resistance occasioned by Flexure.

\begin{tabular}{|c|c|c|c|c|c|c|}
\hline$p$ & 9 & $v^{2}$ & ' & B. & Y. 1 & Y.2 \\
\hline \multirow[t]{3}{*}{238} & $3 \cdot 22$ & 15030 & $4 \cdot 75$ & & 6.71 & 6.98 \\
\hline & & 11 & & & & 5.26 \\
\hline & & 3510 & 1.08 & & $\begin{array}{l}1.21 \\
1.56\end{array}$ & $\begin{array}{l}3.34 \\
1.62\end{array}$ \\
\hline 216 & & 7216 & $2+49$ & $2 \cdot 49$ & $2 \cdot 42$ & $2 \cdot 52$ \\
\hline 144 & & & 1.50 & $1 \cdot 66$ & $1 \cdot 61$ & $1 \cdot 67$ \\
\hline 72 & & & 75 & .83 & $\cdot 80$ & 43 \\
\hline $196 \cdot 5$ & $6 \cdot 12$ & & 1.50 & 1.66 & $1 \cdot 16$ & $1 \cdot 31$ \\
\hline $147^{\circ}$ & & & $1 \cdot 12$ & $1 \cdot 24$ & $\cdot 87$ & $\cdot 93$ \\
\hline 9 & & & 75 & $\cdot 83$ & $\cdot 58$ & $\cdot 65$ \\
\hline $49^{\circ}$ & .53 & & $\cdot 37$ & $\cdot 41$ & -29 & 33 \\
\hline $112 \cdot 5$ & 23 & & $\begin{array}{l}6.00 \\
5.90\end{array}$ & & $7 \cdot 68$ & $6 \cdot 36$ \\
\hline $\begin{array}{r}93 \\
288\end{array}$ & 3.22 & 3415 & $\begin{array}{l}5.50 \\
1.50\end{array}$ & 1.55 & $\begin{array}{l}6.74 \\
1.50\end{array}$ & $\begin{array}{l}5.60 \\
1.58\end{array}$ \\
\hline 288 & $3 \cdot 22$ & 3415 & 1.50 & 1.57 & 1.52 & 1.58 \\
\hline $1+4$ & & & $\cdot 75$ & 78 & $\cdot 76$ & 79 \\
\hline 72 & & & .34 & .39 & $\cdot 38$ & $\cdot 39$ \\
\hline $190^{\circ} 5$ & $6 \cdot 12$ & & $\cdot 75$ & $\cdot 78$ & $\cdot 55$ & • 62 \\
\hline 112.5 & $\cdot 53$ & & 1.50 & & 363 & 3.00 \\
\hline 720 & $3 \cdot 22$ & 5125 & $5 \cdot 90$ & $5 \cdot 90$ & $5 \cdot 72$ & $5 \cdot 9.5$ \\
\hline \multirow[t]{2}{*}{288} & & 3458 & $1 \cdot 64$ & 1.59 & $1 \cdot 54$ & $1 \cdot 60$ \\
\hline & & 860 & • 41 & $\cdot 40$ & $\cdot 38$ & $\cdot 40$ \\
\hline \multirow[t]{2}{*}{288} & $4 \cdot 10$ & $3+48$ & 1.93 & & 1.21 & $1 \cdot 30$ \\
\hline & & 7449 & $2 \cdot 90$ & & $2 \cdot 59$ & $2 \cdot 78$ \\
\hline & $4 \cdot 1$ & & & & & \\
\hline $112 ;$ & $1 \cdot 1$ & & 004 & & 0.08 & 0.02 \\
\hline
\end{tabular}

In the last three experiments, the diameter of the pipe was two inches. The radius of curvature is not ascertained within the tenth of an inch, as Dubuat has not mentioned the thickness of the pipes. The mean error of his formula in fifteen experiments, and of mine in twenty, is $\frac{1}{25}$ of the whole.

[To be continued.] 